Research Article

\title{
Single dose metronidazole, tinidazole and ornidazole in the treatment of bacterial vaginosis - a comparative study
}

\author{
Banapura Ambika ${ }^{1}$, Mamatha K. R. ${ }^{1}$, Geetha Shivamurthy ${ }^{2}$
}

${ }^{1}$ Department of Pharmacology,
${ }^{2}$ Department of Obstetrics and
Gynecology, Bangalore Medical
College \& Research Institute,
Bengaluru, Karnataka, India

Received: 28 June 2016

Accepted: 05 August 2016

*Correspondence to:

Dr. Banapura Ambika,

Email: ambikabanapura101

@ gmail.com

Copyright: (C) the author(s), publisher and licensee Medip Academy. This is an open-access article distributed under the terms of the Creative Commons Attribution Non-Commercial License, which permits unrestricted non-commercial use, distribution, and reproduction in any medium, provided the original work is properly cited.

\begin{abstract}
Background: Bacterial vaginosis (BV) is the most common cause of abnormal vaginal discharge. There is a lack of consensus on the etiologic agents or agents associated with $\mathrm{BV}$, due to polymicrobial nature. There is high recurrence rate of $\mathrm{BV}$ and it is difficult to treat. Metronidazole is the drug of choice but newer nitroimidazoles are better alternatives with long half-lives and better tolerability.

Methods: This was a prospective, comparative, randomized, single blinded study on 120 diagnosed cases of bacterial vaginosis, with symptomatic or asymptomatic abnormal vaginal discharge. Amsel's criteria were used to diagnose bacterial vaginosis as well as to assess the response and classify the patients as cured, partially cured and not cured. Statistical analysis was done by Chi square test. The cure rate was compared considering metronidazole cure rate as gold standard.

Results: At 1 week, the cure rate of tinidazole and ornidazole was $89.5 \%$ in both the groups, and at 4 weeks, it was $84.5 \%$ for both drugs $(\mathrm{P}<0.001)$. Metronidazole showed a cure rate of $65.7 \%$ at 4 weeks.

Conclusions: Tinidazole and ornidazole have better cure rate as compared to metronidazole in cases of bacterial vaginosis.
\end{abstract}

Keywords: Bacterial vaginosis, Metronidazole, Ornidazole, Tinidazole

\section{INTRODUCTION}

Bacterial vaginosis (BV) is a polymicrobial clinical syndrome resulting from replacement of the normal hydrogen peroxide producing Lactobacillus species in the vagina with high concentrations of anaerobic bacteria (e.g., Prevotella and Mobiluncus species), Gardnerella vaginalis, Ureaplasma, Mycoplasma, and numerous fastidious or uncultivated anaerobes. ${ }^{1}$

There is a lack of consensus on the etiologic agents or agents associated with $\mathrm{BV}$, due to polymicrobial nature. $\mathrm{BV}$ is the most common cause of vaginal discharge occurring in up to $30 \%$ of women. ${ }^{2}$ The incidence is increased among women who have multiple sex partners, use an intrauterine device for contraception and douche routinely for hygiene. ${ }^{3,4}$

Thus treatment has been based on empiricism generally with metronidazole or clindamycin which were chosen for their activity against many anaerobic organisms.

According to CDC 2015 guidelines, metronidazole is the drug of choice for $\mathrm{BV}$, a five-nitroimidazoles derivative, with half-life of 7.9-8.8 hours. ${ }^{5-7}$ Clinical cure rate is about $84 \%$ but unfortunately long-term follow-up shows relapse rate of $70 \% .^{8}$

The newer nitroimidazoles, tinidazole and ornidazole are structurally similar to metronidazole, with long half-lives 
of 14-14.7 hours, 14.1-16.8 hours for tinidazole and ornidazole respectively and are well tolerated resulting in better efficacy, simple dosing schedules. ${ }^{7,9,10}$ Longer halflife is said to have adequate control over pathogenic bacteria. Cure rates of both the drugs are approximately $96-97 \% .^{10,11}$

Bacterial vaginosis is the most common cause of vaginal discharge and asymptomatic women are less likely to seek treatment for the same and thus are more prone to acquire other sexually transmitted infections. ${ }^{4}$

The qualities of tinidazole and ornidazole with respect to their longer half-lives and their side effect profile as compared to oral metronidazole may result in being more efficacious for the treatment of BV. There are limited numbers of studies comparing drugs in this condition. Hence this prospective, comparative, study was conducted to compare the efficacy and safety of metronidazole ( $2 \mathrm{~g})$, tinidazole $(2 \mathrm{~g})$, and ornidazole (1.5 $\mathrm{g}$ ), all given orally as a single dose in the treatment of bacterial vaginosis in our tertiary care hospital.

The objective of the present study was to compare the efficacy and safety of single oral dose metronidazole, tinidazole, ornidazole, in bacterial vaginosis, to assess the risk factors for the development of bacterial vaginosis.

\section{METHODS}

It is a prospective, comparative, unmasked study, involving diagnosed cases of bacterial vaginosis in Department of obstetrics and gynaecology, Vanivilas hospital, attached to Bangalore medical college and research institute, Bengaluru. The study period was December 2015 to May 2016. Simple Random sampling technique was used for sampling.

\section{Inclusion criteria}

All of the following criteria were required of candidates for enrolment are of age at least 18 years, capable of providing written informed consent, a negative pregnancy test on the day of enrolment, able to follow the study protocol, willing to forego coitus for days 1-10 of study participation, willing not to douche or use any intravaginal products throughout participation, including tampons, medications, and devices, willing to avoid drinking any alcohol from 24 hours before through 72 hours after taking study medication and premenopausal status.

\section{Exclusion criteria}

The following characteristics excluded participants from participation: Subjects not willing to participate in the study, identification of fungal elements or trichomonads by microscopic examination of vaginal discharge, lesions caused by herpes simplex virus or human papillomavirus on gross examination, presence of another vaginal, vulvar, or medical condition which might confound assessment of response to study treatment or under treatment for cervical neoplasia during participation, history of hypersensitivity to 5-nitroimidazole agents or treatment with any 5-nitroimidazole, antifungal agent, or clindamycin within 14 days of study entry, or with any investigational drug within 30 days of study entry, presently breastfeeding or menstruating at diagnosis.

After obtaining clearance and approval from the Institutional Ethics Committee of Bangalore medical college and research institute, and written informed from participants, patients in the age group of 18-45 years, diagnosed as having $\mathrm{BV}$, fulfilling inclusion and exclusion criteria, were included in this study. Bacterial vaginosis was diagnosed by Amsel's criteria in both symptomatic and asymptomatic groups. Amsel's criteria consist of four factors.

- Homogenous, milky or creamy vaginal discharge

- $\mathrm{pH}$ of secretion above 4.5

- Fishy odour with or without addition of $10 \%$ $\mathrm{KOH}$

- Presence of clue cells on microscopic examination

Any three criteria out of four are necessary to diagnose bacterial vaginosis. Their demographic data, history, clinical and gynecological examination findings were recorded in case record forms. Willing participants were administered a questionnaire which included questions related to most common risk factors for development of bacterial vaginosis. The characteristics like income, level of education, socioeconomic status, contraceptive use, hygienic practices and sexual risk behaviors were assessed in questionnaire. 120 patients were divided into 3 equal groups 40 cases each. Each group received metronidazole $2 \mathrm{~g}$, tinidazole $2 \mathrm{~g}$ and ornidazole $1.5 \mathrm{~g}$ respectively, as single oral dose. Baseline investigations consisted of i) vaginal ph measurement - by directly dipping a $\mathrm{pH}$ strip in vagina ii) gram staining of the vaginal smear iii) wet mount (KOH mount). Follow up visits were done, one at the end of one week and another, at the end of four weeks. At each follow up visit, the patients underwent investigations like vaginal $\mathrm{pH}$ measurement, direct microscopy and gram staining of the vaginal smear, and also, $\mathrm{KOH}$ mount or wet mount of vaginal smears. The patients adverse drug reactions were recorded in a separate proforma. Efficacy was assessed by response to the drugs by using Amsel's criteria and patients fall into one of the four groups, based on the response -

- Complete cure- none of the four criteria are present.

- Improvement in the disease - only one criterion are present

- $\quad$ Partial cure - two criteria are present 
- Failure of treatment - three or four criteria are present

Safety assessment was done by monitoring adverse drug reactions. The data was analysed and presented in percentages, chi square test was applied to compare the cure rates of tinidazole, ornidazole with cure rates of metronidazole. Value of $p<0.05$ was considered as significant.

\section{RESULTS}

In the present study, the mean age of the patients was $27 \pm 3$ years with $70 \%$ of them with primary level of education and from low socioeconomic background. 120 women were enrolled, with 40 in each group and 6 patients were lost to follow up at end of one week. The commonest symptom was vaginal discharge and $20 \%$ of the women were asymptomatic. The other less common complaints were lower back pain, fatigue, lower abdominal pain. Proper menstrual hygiene was practiced in $62.5 \%$ of women, $62.5 \%$ had tubal ligation, $40 \%$ of the women used intrauterine contraceptive device, $3.3 \%$ of them reported of using vaginal condoms. No women reported of having multiple sex partners. None disclosed history of sexually transmitted infections. $75 \%$ of the women practiced douching as given in Table 1.

Table 1: Patient characteristics.

\begin{tabular}{|lll|}
\hline Characteristics & Yes $\mathbf{n}(\%)$ & No n (\%) \\
\hline Symptomatic & $96(80)$ & $24(20)$ \\
\hline Primary education & $84(70)$ & $36(30)$ \\
\hline Douching & $90(75)$ & $30(25)$ \\
\hline Used IUCD & $48(40)$ & $72(60)$ \\
\hline Tubectomised & $75(62.5)$ & $45(37.5)$ \\
\hline $\begin{array}{l}\text { Proper menstrual } \\
\text { hygiene }\end{array}$ & $75(62.5)$ & $45(37.5)$ \\
\hline Used vaginal condoms & $4(3.3)$ & $116(96.7)$ \\
\hline History of STI & 0 & $120(100)$ \\
\hline $\begin{array}{l}\text { History of multiple } \\
\text { sexual partners }\end{array}$ & 0 & $120(100)$ \\
\hline
\end{tabular}

Metronidazole showed a cure rate of $71 \%$ at 1 week and $65.7 \%$ at 4 weeks. With tinidazole and ornidazole the cure rates were similar and they were $89.5 \%$ and $84.5 \%$ at 1 week and 4 weeks respectively as presented in Table 2 and 3.

Table 2: Cure rates of drugs in bacterial vaginosis at one week.

\begin{tabular}{|lll|}
\hline Drug & Cure rate $(\%)$ & p value* \\
\hline Metronidazole & $27 / 38(71)$ & \\
\hline Tinidazole & $34 / 38(89.5)$ & $<0.05$ \\
\hline Ornidazole & $34 / 38(89.5)$ & $<0.05$ \\
\hline *ure rates of tinidazole and ornidazole compared to
\end{tabular}
metronidazole, $\mathrm{p}<0.05$ was considered significant.
Table 3: Cure rates of drugs in bacterial vaginosis at four weeks.

\begin{tabular}{|lll|}
\hline Drug & Cure rate $(\%)$ & p value* \\
\hline Metronidazole & $25 / 38(65.7)$ & \\
\hline Tinidazole & $32 / 38(84.5)$ & $<0.05$ \\
\hline Ornidazole & $32 / 38(84.5)$ & $<0.05$ \\
\hline
\end{tabular}

*Cure rates of tinidazole and ornidazole compared to metronidazole, $\mathrm{p}<0.05$ was considered significant.

The most common adverse drug reactions reported were bad taste $(n=10)$, diarrhoea $(n=12)$, nausea $(n=5)$, and headache $(n=6)$. Total number of adverse drug reactions (ADR) was 12, 10 and 11 in metronidazole, tinidazole, ornidazole group respectively as shown in Table 4 .

Table 4: Adverse drug reactions.

\begin{tabular}{|llll|}
\hline ADR & $\begin{array}{l}\text { Metronid- } \\
\text { azole }\end{array}$ & $\begin{array}{l}\text { Tinid- } \\
\text { azole }\end{array}$ & $\begin{array}{l}\text { Ornid- } \\
\text { azole }\end{array}$ \\
\hline Bad taste & $3(25 \%)$ & $4(40 \%)$ & $3(27.2 \%)$ \\
\hline Diarrhoea & $4(33.3 \%)$ & $3(30 \%)$ & $5(45.5 \%)$ \\
\hline Headache & $3(25 \%)$ & $1(10 \%)$ & $2(18.2 \%)$ \\
\hline Nausea & $2(16.7 \%)$ & $2(20 \%)$ & $1(9.1 \%)$ \\
\hline Total & 12 & 10 & 11 \\
\hline
\end{tabular}

\section{DISCUSSION}

Bacterial vaginosis (BV) is a disease with unknown aetiology, characterised by loss or reduction of lactobacilli and increased number of anaerobes and Gram-negative rods. ${ }^{12}$ It is one of the most frequent vaginal infections, and the most common symptom is malodours discharge. Treatment of BV requires the usage of a proper antimicrobial drug against anaerobic agents without affecting normal vaginal flora.

Sociodemographic factors such as education, income, douching are associated with BV. ${ }^{13-16}$ Genital hygiene practices are also known to be associated with bacterial vaginosis. ${ }^{17}$ In this study, majority $(70 \%)$ of women were from low socioeconomic group and practiced douching (75\%) with $30 \%$ not having primary education. $40 \%$ of the women used intrauterine contraceptive device. All these factors may contribute to the recurrence of $\mathrm{BV}$ as there is evidence that incidence of $\mathrm{BV}$ is increased among women who, use an intrauterine device for contraception, douche routinely for hygiene, have multiple sex partners. $^{3,4,16}$

According to CDC guidelines, metronidazole is the drug of choice for bacterial vaginosis. However, adverse effects due to metronidazole are frequent and this may lead to problems with adherence to a 7-day course of treatment and subsequently result in treatment failure. ${ }^{18}$ Consequently, other drugs of the nitroimidazoles class have been explored as alternatives to metronidazole for the treatment of BV. Half-life of metronidazole is 7.9 to 8.8 hours. $^{19}$ Tinidazole and ornidazole can be better 
alternatives as they have longer half-lives of 14-14.7 hours and 14.1-16.8 hours, respectively. The half-life of the drug is important as longer half-life has better control over pathogenic bacteria. ${ }^{12}$

The present study was taken up to compare single dose tinidazole, ornidazole with metronidazole in BV. In the metronidazole group the cure rate was $71 \%$ at the end of 1 week and $65.7 \%$ at the end of 4 weeks. The study done by Thulkar et al, at AIIMS, New Delhi was the first study comparing four nitroimidazoles in Indian population. It showed high cure rates of $88.4 \%$ and $77.9 \%$ at one and four weeks respectively. ${ }^{11}$ The cure rates with metronidazole in our study are comparable to the results in a review article by Larsson et al. with a cure rate of 60 $-70 \%$ at the end of four-weeks. ${ }^{8}$ The lower cure rates in our study could be due to differences in various other hygienic practices.

Oral tinidazole has been used to treat bacterial vaginosis for over 25 years in a number of different dosage regimens. Studies by Carmona et al and Mohanty et al showed minor enhanced in vitro activity against $G$. vaginalis with tinidazole compared to metronidazole. ${ }^{20,21}$ In an antimicrobial susceptibility testing to metronidazole and tinidazole, when performed on 470 vaginal isolates from women with bacterial vaginosis the overall spectrum of activity was very similar. ${ }^{22}$

Tinidazole shows activity against anaerobes similar to that of metronidazole with slightly greater activity against G. vaginalis which is one of the major organisms causing BV. ${ }^{23}$ In 2007 Nailor and Sobel reviewed 21 clinical efficacy studies evaluating tinidazole for bacterial vaginosis and concluded that compared with placebo, tinidazole in all studied regimens consistently demonstrated efficacy in eradicating signs and symptoms of BV. This could be attributed to tinidazole's minor but possibly relevant antimicrobial as well as pharmacokinetic advantages such as longer half-life, better tolerated with less incidence of metallic taste. ${ }^{24}$

In present study tinidazole showed cure rates of $89.5 \%$ at the end of one week and $84.5 \%$ at the end of four weeks which is less compared to cure rates in the study done by Thulkar et al with cure rates of $100 \%$ and $97.7 \%$ at 1 week and 4 weeks respectively. In a multicenter, randomized study by Schindler et al, a single oral dose of $2 \mathrm{~g}$ tinidazole has shown $97 \%$ success rate compared to $84 \%$ with $400 \mathrm{mg}$ metronidazole for five days. ${ }^{25}$

In a study conducted by Buranawarodomkul, single dose of $2 \mathrm{~g}$ tinidazole was compared to $1 \mathrm{~g}$ metronidazole for 7 days. The efficacy rates after 2 weeks were $86 \%$ and $92 \%$ for tinidazole and metronidazole respectively, but the difference was said to be statistically insignificant. ${ }^{26}$ Another study comparing single dose tinidazole and 7 days metronidazole produced the efficacy rates of $65 \%$ and $74 \%$ for tinidazole vs metronidazole, respectively. ${ }^{27}$ These two studies showed slightly higher efficacy rates with metronidazole. Although a single $2 \mathrm{~g}$ dose of tinidazole appears more effective than a single $2 \mathrm{~g}$ dose of metronidazole, it may be less effective than seven days of metronidazole. ${ }^{28}$

In a randomized controlled trial, with two regimens of tinidazole of $1 \mathrm{~g}$ once daily for 5 days and $2 \mathrm{~g}$ once daily for 2 days, vs placebo, both the regimens proved to be effective with comparable gastrointestinal side effects in all the three arms. ${ }^{29}$ Due to the fact that FDA criteria for cure have changed over the years it is difficult to compare cure rates of tinidazole to other licensed products for the treatment of $\mathrm{BV}^{28}$

Tinidazole and ornidazole have greater antimicrobial activity than metronidazole as per Mayo clinic proceedings of $1987 .{ }^{30}$ In the present study cure rates with ornidazole was $89.5 \%$ at end of one week and $84.5 \%$ at end of four weeks. This is unlike the high cure rates observed in a study by Thulkar et al with cure rates of $100 \%$ and $97.7 \%$ at one week and four weeks respectively. ${ }^{11}$ In a study by Erkkola et al, single oral dose of ornidazole $1.5 \mathrm{~g}$ in 24 women with BV, conducted in Finland, showed subjective improvement in $96 \%$ of the patients. ${ }^{31}$ These studies which used ornidazole are comparable to present study as the dose of ornidazole and follow up period was similar. The reasons for low cure rates in the present study compared to other studies could be the differences in hygienic practices among women and also sexual risk behaviours.

The most common adverse effects overall, reported in the study were bad taste (30.3\%), diarrhoea (36.4\%), headache $(18.2 \%)$ and nausea $(15.1 \%)$. The most common adverse effect in tinidazole group was bad taste $(40 \%)$ and in ornidazole group was diarrhoea $(45.5 \%)$. No serious adverse effect was reported with any of the drugs. All the three drugs were well tolerated.

Cure rates with ornidazole and tinidazole were similar, both tinidazole and ornidazole proved significantly better than metronidazole in efficacy ( $p<0.05)$, which could be due to longer half-lives with tinidazole and ornidazole compared to metronidazole.

Additional research is needed to better understand the socio-cultural risk factors surrounding this condition. There is still a need for continued basic studies on the vaginal flora, local immunity to the flora and hostparasite interactions as an aid when designing informative clinical studies in case of $\mathrm{BV}{ }^{8}$

Limitations of this study were, risk factors and adverse effects of drugs were self-reported, and it is possible that there was under-reporting of risk behaviours and adverse effects related to drugs. Furthermore, because there is strong evidence in literature that $\mathrm{BV}$ is associated with STIs including HIV further studies are needed to understand the potential role of screening and treatment of $\mathrm{BV}$ in STI/HIV prevention programmes. 


\section{CONCLUSION}

When given as a single oral dose tinidazole and ornidazole had similar cure rate which was higher than that of metronidazole in the treatment of bacterial vaginosis. All the three drugs were well tolerated with no major adverse effects with any of the drugs.

\section{ACKNOWLEDGEMENTS}

The authors would like to thank the professor and head of the department, Dr. T. Nagarathnamma, faculties and post graduate students from the Department of Microbiology, Bangalore Medical College \& Research Institute, Bengaluru for their support in conducting the project work.

Funding: No funding sources Conflict of interest: None declared

Ethical approval: The study was approved by the Institutional Ethics Committee

\section{REFERENCES}

1. Koumans EH, Sternberg M, Bruce C, Mc Quillan G, Kendrick J, Sutton M, et al. The prevalence of bacterial vaginosis in the United States, 2001-2004: associations with symptoms, sexual behaviors, and reproductive health. Sex Transm Dis. 2007;34:8649.

2. National Family Health Survey 2: 1998-99, (NFHS II), Mumbai. International Institute for Population Sciences. 1999:307-14.

3. Barbone F, Austin H, Louv WC, Alexander WJ. A follow-up study of methods of contraception, sexual activity, and rates of trichomoniasis, candidiasis, and bacterial vaginosis. Am J Obstet Gynecol. 1990;163:510-4.

4. Avonts D, Sercu M, Heyerick P, Vandermeeren I, Meheus A, Piot P. Incidence of uncomplicated genital infections in women using oral contraception or an intrauterine device: a prospective study. Sex Transm Dis. 1990;17:23-9.

5. Josey W, Schwebke J. The polymicrobial hypothesis of bacterial vaginosis causation: a reassessment. Int J STD AIDS. 2008;19:152-4.

6. 2015 CDC STD Treatment Guidelines. Available at http://www.cdc.gov/std/tg2015/bv.htm. Accessed on 01 August 2016.

7. Mattila J, Mannisto PT, Mantyla R, Nykanen S, Lamminsivu U. Comparative pharmacokinetics of Metronidazole and Tinidazole as influenced by administration route. Antimicrob Agents Chemother. 1983;23:721-5.

8. Larsson PG, Forsum U. Bacterial vaginosis-A disturbed bacterial flora and treatment enigma. APMIS. 2005;113:305-16.

9. Martin C, Bruguerolle B, Mallet MN, Condomines M, Sastre B, Gouin F. Pharmacokinetics and tissue penetration of a single dose of Ornidazole. Antimicrob Agent Chemother. 1990;34:1921-4.

10. Tripathi KD. antiamoebic and other antiprotozoal drugs In: tripathi M, Essentials of medical pharmacology. 7th Edition. New Delhi. Jaypee Brothers; 2014: 839.

11. Thulkar J, Kriplani A, Agarwal N. A comparative study of oral single dose of metronidazole, tinidazole, secnidazole and ornidazole in bacterial vaginosis. Indian J Pharmacol. 2012;44:243.

12. Fredricks DN, Fiedler TL, Thomas KK, Oakley BB, Marrazzo JM. Targeted PCR for detection of vaginal bacteria associated with bacterial vaginosis. J Clin Microbiol. 2007;45(10):3270-6.

13. Bradshaw CS, Morton AN, Garland SM, Morris MB, Moss LM, Fairley CK. Higher-risk behavioral practices associated with bacterial vaginosis compared with vaginal candidiasis. Obstet Gynecol. 2005;106:105-14.

14. Hellberg D, Nilsson S, Mardh PA. Bacterial vaginosis and smoking. Int $J$ STD AIDS. 2000;11:603-6.

15. Mbizvo ME, Musya SE, Stray-Pedersen B, Chirenje Z, Hussain A. Bacterial vaginosis and intravaginal practices: association with HIV. Cent Afr J Med. 2004;50:41-6.

16. Hutchinson KB, Kip KE, Ness RB. Vaginal douching and development of bacterial vaginosis among women with normal and abnormal vaginal microflora. Sex Transm Dis. 2007;34:671-5.

17. Bukusi EA, Cohen CR, Meier AS, Waiyaki PG, Nguti R, Njeri JN, et al. Bacterial vaginosis: risk factors among Kenyan women and their male partners. Sex Transm Dis. 2006;33:361-7.

18. Brandt M, Abels C, May T, Lohmann K, SchmidtsWinkler I, Hoyme B. Intravaginally applied metronidazole is as effective as orally applied in the treatment of bacterial vaginosis, but exhibits significantly less side effects. Eur J Obstet Gynecol Reprod Biol. 2008;141:158-62.

19. Kurt O, Girginkardeşler N, Balcioğlu IC, Ozbilgin A, Ok UZ. A comparison of metronidazole and single-dose ornidazole for the treatment of dientamoebiasis. Clin Microbiol Infect. 2008;14:601 -4 .

20. Carmona O, Silva H, Acosta H. Vaginitis due to Gardenerella vaginalis treatment with tinidazole. Curr Ther Res. 1983;22:898-904.

21. Mohanty KC, Deighton R. Comparison of $2 \mathrm{~g}$ single dose of metronidazole, nimorazole and tinidazole in the treatment of vaginitis associated with Gardnerella vaginalis. J Antimicrob Chemother. 1987;19:393-9.

22. Austin MN, Meyn LA, Hillier SL. Susceptibility of vaginal bacteria to metronidazole and tinidazole. Anaerobe. 2006;12:227-30.

23. Armstrong NR, Wilson JD. Tinidazole for bacterial vaginosis. International Journal of Women's Health. 2009;1:59-65. 
24. Nailor MD, Sobel JD. Tinidazole for bacterial vaginosis. Expert Review of Anti-infective Therapy. 2007;5(3):343-8.

25. Schindler EM, Thamm H, Ansmann EB, Sarnow E, Schindler AE. Treatment of bacterial vaginitis. Multicenter, randomized, open study with tinidazole in comparision with metronidazole. Fortschr Med. 1991;109:138-40.

26. Buranawarodomkul $\mathrm{P}$, Chandeying $\mathrm{V}$, Sutthijumroon S. Seven day metronidazole versus single dose tinidazole as therapy for nonspecific vaginitis. J Med Assoc Thai. 1990;73:283-7.

27. Sanz F, Hernanz A, Sancher E. Comparative trial of metronidazole versus tinidazole in the treatment of nonspecific vaginitis. Rev Esp Obst y Gin. 1985;44:717-20.

28. Schwebke JR, Desmond RA. Tinidazole versus Metronidazole for the Treatment of Bacterial Vaginosis. Am J Obstet Gynecol. 2011;204(3):211.
29. Livengood CH, Ferris DG, Wiesenfeld HC, Hillier SL, Soper DE, Nyirjesy P, et al. Effectiveness of Two Tinidazole Regimens in Treatment of Bacterial Vaginosis: A Randomized Controlled Trial. Obstetrics \& Gynaecology. 2007;110:302-9.

30. Rosenblatt JE, Edson RS. Symposium on antimicrobial agents. Metronidazole. Mayo Clin Proc. 1987;62:1013-7.

31. Erkkola R, Jarvinen H. Single dose of Ornidazole in the treatment of bacterial vaginosis. Ann Chir Gynaecol Suppl. 1987;202:94-6.

Cite this article as: Ambika B, Mamatha KR, Shivamurthy G. Single dose metronidazole, tinidazole and ornidazole in the treatment of bacterial vaginosis - a comparative study. Int J Basic Clin Pharmacol 2016;5:1966-71. 